Psychological Medicine, 1998, 28, 1-8. Printed in the United Kingdom

(C) 1998 Cambridge University Press

\title{
EDITORIAL
}

\section{Sex and depression ${ }^{1}$}

Sex differences in rates of depressive disorder have not been convincingly explained, and this reflects a more general failure of research to provide a comprehensive aetiological account of depression. The difference can be used as a probe for evaluating the research base of integrative models of depressive disorder (e.g. Akiskal \& McKinney, 1975). It is particularly likely to be illuminating if the causes of the sex difference do not overlap completely the causes of depression itself. While there have been many reviews in the area (Weissman \& Klerman, 1977; Kessler \& McRae, 1981; Wolk \& Weissman, 1995; Bebbington, 1996), this point has not been adequately expressed.

Several lines of investigation are necessary for assessing the relative importance of social, psychological and biological influences: the epidemiological study of macrosocial variables and of age effects; temperament, personality, and attributional and coping styles; the experience of psychosocial adversity; and the possibility of increased susceptibility to some forms of stress in women. Both the tendency to affiliation and the requirement for social support may differ by sex. The particular strains of the roles available to women may increase their risk of depression. Possible genetic explanations of the sex difference are of special relevance because of their implications for biological differences. The latter can also be studied directly: hormonal theories in particular must be evaluated.

\section{EPIDEMIOLOGICAL SUPPORT FOR A SEX DIFFERENCE}

Community surveys are the best source for assessing sex differences in depressive disorder. (Bebbington, 1994; Kessler et al. 1993; Meltzer et al. 1995; Wolk \& Weissman, 1995). The sex ratio is maintained in all Western societies, and in most Non-western studies as well. Some authors have suggested that it is declining (Srole \& Fischer, 1980), but recent cohort studies do not reveal much change (Wolk \& Weissman, 1995).

\section{HIGH RISK GROUPS}

If higher rates of depression in women were due, for instance, to a universal biological vulnerability, the sex ratio ought to be unaffected by sociodemographic attributes. This is certainly not true, for example, of the effect of marital status, since sex ratios typically differ in the single, the married and the post-marital. Two situations would be of interest: where more women than men occupy a social category with high rates of depression, and where women in a given category seem to be at a special disadvantage. In the second case, the reason for the disadvantage then has to be explained.

It has been argued that being married brings more stress for women than for men (Weissman \& Klerman, 1977; Paykel \& Rowan, 1979; Weissman et al. 1984). Many studies have found that young married women looking after small children are particularly at risk (Baldwin, 1971; Grad de Alarcon et al. 1975; Moss \& Plewis, 1977; Richman, 1974, 1977; Brown \& Harris, 1978; Bebbington et al. 1981 a 1984; Ensel, 1982). However, marital status has different associations with effective disorder in different cultures. Married women are at low risk of disorder in Mediterranean countries (Mavreas et al. 1986; Vázquez-Barquero et al. 1987), in rural New Zealand (Romans-Clarkson et al. 1988) and in British orthodox Jews (Loewenthal et al. 1995). These societies all accord a high

* Address for correspondence: Professor P. E. Bebbington, University College Medical School, Department of Psychiatry and Behavioural Sciences (Whittington Site), Archway Wing 1st Floor, Whittington Hospital, Highgate Hill, London N19 5NF. 
value to the home-making role. This suggests not only that social variables are important in determining the sex ratio for depression, but that the association with relatively simple sociodemographic factors is itself affected by more subtle sociocultural influences.

In most Western societies women are still less likely to be employed than men. Employment generally has beneficial affects on psychological health: it brings interest, income, fulfilment, social contacts and status, and provides structure and a sense of control (Jahoda, 1982; Krause \& GeyerPestello, 1985). The availability of these benefits is likely to differ both among women, and between men and women. The advantages of employment are weaker in married women (Roberts \& O'Keefe, 1981; Roberts et al. 1982; Warr \& Parry, 1982), more so if they have children (McGee et al. 1983; Parry, 1986), most so when the children are of pre-school age (Haw, 1995). Full-time employment is particularly demanding (Cleary \& Mechanic, 1983; Elliott \& Huppert, 1991). The most likely explanation for these findings is role conflict and overload. Thus, part of the excess of depressive disorders in women may be related both to their reduced involvement in employment and to the particular strains they are exposed to if they do work.

Overall, the results that emerge from the epidemiological study of macrosocial variables are suggestive. They are also inconsistent, probably because they are imperfect markers of variables much more intimately and consistently related to the individual experience of depression, that is, subjects' immediate personal circumstances and their psychological attributes. These may explain both the existence of socially defined high risk groups and why high risk has a different social distribution in different localities and cultures.

\section{AGE, SEX AND DEPRESSION}

In assessing the origins of sex differences in depression we must consider the major effect of age on prevalence and incidence. In prepubertal children there is, if anything, a male predominance in depressive symptoms and disorders (Anderson et al. 1987; Kashani \& Carlson, 1987; Fleming \& Offord, 1990), while during adolescence the female: male (F:M) ratio approaches the $2: 1$ value seen in adults (Rutter et al. 1976; Cohen et al. 1993). This change in ratio appears to be specific to depression (Rutter, 1991; Angold \& Rutter, 1992).

In adulthood, the sex ratio tends to decline with age (Bebbington, 1988). The interesting question is whether this can be related to the timing of the menopause. Jorm's (1987) meta-analysis suggested that the sex ratio was much reduced at the ends of the life span, but was maintained for some time after the menopausal years. However, the recent British National Survey of Psychiatric Morbidity (Melzer et al. 1995; Bebbington et al. 1998) suggests that after age 55, the sex ratio changes, due mainly to a fall in female rates. Considerable weight should be placed on these findings because of the size and representativeness of the sample.

Thus, it remains possible that the high $\mathrm{F}: \mathrm{M}$ ratio is restricted to the period of female fertility and declines afterwards due to a reduction in female rates. This might have hormonal origins: certainly Bebbington et al. (1998) found it to be independent of changes in marital status, child-care arrangements and employment.

Linking the hormonal changes of puberty with increases in female depressive disorder requires, as a first step, direct hormonal measurement in relation to mood. However, the effect of sex hormone levels is trivial beside the impact of social factors (Brooks-Gunn \& Warren, 1989), and relates more to depressed mood than to formal depressive disorder. Moreover, several studies have found that controlling for age eliminates the contribution of pubertal stage to the adolescent increase in rates of depressive disorders in girls (Brooks-Gunn \& Warren, 1989; Paikoff et al. 1991; Angold \& Rutter, 1992). Despite one well conducted exception (Patton et al. 1996), the evidence favours the importance of being in a pubertal cohort over the personal experience of puberty: this is easier to explain in social terms.

Thus, the relationship between the sex difference and age suggests important changes around the time of puberty. While there is probably a genuine post-menopausal fall in rates in women, this does not seem closely related to the timing of the actual hormonal changes. The thrust of the evidence 
is, therefore, in favour of regarding these as times of social and psychological transition rather than hormonally regulated.

\section{SEX HORMONES AND DEPRESSION}

What about more direct evidence linking hormone status to depressive disorder? These have some face validity: oestradiol and progesterone seem to modulate neurotransmitter and neuroendrocrine systems, including those involving monoamines, and there are transitions in women's lives characterized by hormonal shifts that are also associated with mood disturbance.

I have reviewed elsewhere the extremely complicated evidence in this area (Bebbington, 1996). The real difficulty in attributing the sex difference to female sex hormones arises from our access to a more plausible neuroendocrine hypothesis involving glucocorticoids. This offers an explanation for a range of other neurohumoral phenomena and a mechanism whereby extrinsic stress may result in the features of depressive disorder (Dinan, 1994; Checkley, 1996). It links over-activation of the hypothalamico-pituitary axis and the associated hypercortisolism with the changes in the central monoaminergic pathways thought to underlie depression and the actions of antidepressants. These changes will probably turn out to be the major hormonal concomitants of depressive disorder. Unfortunately, for our purpose, they cannot explain the sex difference: specifically, cortisol responses are not found to be increased before menstruation, while the function of the HPA axis in general does not differ by sex in the required manner (Allen \& Pitts, 1984; Ansseau et al. 1987; Maes et al. 1989 a; Hunt et al. 1989).

\section{NO ROLE FOR GENETICS}

The failure to find a convincing sex-related biological mechanism for depression that would account for the sex difference has its parallel in genetic studies. The model with the most potential in this area is one based on multiple threshold liability. This assumes that the familial liability to a disorder is continuously distributed, comprising both genetic factors and familial-environmental effects. Depression in women can be conceived as a broad form of disorder with a lower threshold than the narrow male form. Under this model the relatives of male probands will be more frequently affected, because in them the loading of familial factors will be greater (Carter, 1969). In practice, the relatives of male depressives are not at higher risk than the relatives of female depressives (Merikangas et al. 1985; Kupfer et al. 1989), so it seems that the sex ratio must be explained in terms of extra-familial influences. This still allows for genetic effects in the transmission of depression, merely averring that they do not cause the sex difference.

As it is extremely unlikely that biological differences between women would be unaffected by intrafamilial (specifically genetic) factors, the failure of genetic explanations inevitable moves the focus of interest onto the physical and social environment.

\section{PSYCHOLOGICAL EXPLANATIONS}

The psychological characteristics associated with depression might serve as an explanation if it could be demonstrated that they are more typical of normal women than men. In fact there has been surprising little research into sex differences in ordinary cognitive style, and when differences are demonstrated, they are not always in the right direction. Moreover, the attitudes and attributions supposed to contribute to the causation of depression may merely be symptoms of it (e.g. Lewinsohn et al. 1981; Haaga et al. 1991). The grail is to find markers of attributional style that can be detected during periods of well-being (Power, 1990); this underlying style might then be activated in appropriate circumstances. One example is the 'interacting cognitive subsystems' postulated by Teasdale \& Barnard (1993; Teasdale, 1995), whereby specific maladaptive attitudes can be reactivated by specific experiences. While this has considerable intuitive appeal and leads to testable hypotheses, no work relevant to sex differences has been carried out. Moreover, as the dysfunctional 
systems are held to be the residues of prior depressive states, the theory explains recurrences rather than initial episodes.

A number of authors have tried to link styles of coping with sex differences (Billings \& Moos, 1984; Fondicaro \& Moos, 1987; Bruder-Mattson \& Hovanitz, 1990), but with little success. NolenHoeksema (1987, 1990) has argued that the development of depressive disorder is crucially determined by individuals' responses to an initial lowering of mood. Ruminative styles, more often seen in women (Nolen-Hoeksema et al. 1994), are particularly likely to result in an increasing spiral of depression, while the more active styles of coping typical of men appear to abort it.

The two most elaborate psychological formulations of depression are those of Abramson and her colleagues $(1978,1989,1993)$ and of Beck et al. (1980). Scrutiny of these models suggests they might be rather good at explaining sex differences in depression. However, little specific research has been done, and what there is inconclusive and confusing (Calicchia \& Pardine, 1984; Hirschfeld et al. 1984; Martin et al. 1984; Sowa \& Lustman, 1984). The link between cognitions and early social experience and socialization is a fruitful topic for investigation, but again the quantity and quality of research has been inadequate.

\section{ADVERSITY AND VULNERABILITY}

Women may be subject to more, or more upsetting, life events than men. Some researchers have found this (Brown \& Birley, 1968; Bebbington et al. 1981 b, 1991), others have not (Uhlenhuth \& Paykel, 1973a, b; Uhlenhuth et al. 1974; Thoits, 1982; Perugi et al. 1990). Women may be exposed to more chronic problems than men (Radloff, 1975; Pearlin \& Johnson, 1977; Pearlin \& Lieberman, 1977). Bebbington and his colleagues (1991) found that, although recent adversity was indeed commoner in women, it could not account adequately for their excessive frequency of minor affective disorder.

Early hardships and misfortunes may be more serious candidates for explaining high female rates of depression. The direct effects of physical abuse are quite clear during childhood, and suggest a link with adult depressive disorder, since they lead to depression, low self-esteem, hopelessness, and an external locus of control (Allen \& Tarnowski, 1989). Roesler \& McKenzie (1994) state that abuse in childhood leads to adult depression, that sexual abuse is worse in this respect than physical abuse and that forced sexual abuse is the worst of the lot. Sexual abuse is commoner in females (Nuttall \& Jackson, 1994), and might go a considerable way to explaining the adult sex difference in depressive disorders. Bifulco and her colleagues (1991) found major effects of sexual abuse on rates of depression in their working class London women. Kuyken \& Brewin (1994) reported that, of 35 depressed women who had been abused in childhood, 30 had experienced 'flashbacks' of the abuse in the previous week. Abuse induces the sorts of cognitive changes that would be expected to mediate the link with adult depression (Rose et al. 1994; Brewin, 1996). This is an under-researched area as an explanation of sex differences in the experience of depression. It may be very important.

It is also possible that women have a special susceptibility to life events (Bebbington et al. $1981 b$; Cooke $\&$ Hole, 1983), itself requiring explanation. Certain subgroups of women, for instance those caring for young children, may be especially prone to depressive responses to life events (Brown \& Harris, 1978; Bebbington et al. 1984).

Particular events may have more impact on women, specifically those affecting close emotional ties. Kessler \& McLeod (1984) and Turner \& Avison (1989) developed the 'cost of caring' hypothesis: women care more for others and are more affected by events affecting others rather than themselves. Turner \& Avison (1989) found that women were equally vulnerable to self-focused events, but more so than men to events affecting others.

The importance for women of events affecting intimate relationships brings us to a final vulnerable group, people with low social support (Alloway \& Bebbington, 1987). These appear to be at particular risk of developing depression, at least partly because they are more vulnerable to the experience of psychosocial adversity. Women might be at high risk of depression because they have less access to social support, or because they are more vulnerable to its absence. In fact there 
is no evidence whatever that women have reduced social support, as is only to be expected in view of their affiliative style. Turner \& Marino (1994) claim that the epidemiology of poor social support is very similar to that of depression, with the exception of sex. In other words, the high rates of depression in women cannot be blamed on poor social support. Thus, women when depressed are likely to use more prosocial coping strategies than men (Hobfoll et al. 1994), but at the same time low social support is associated with a greater tendency toward (maladaptive) rumination (NolenHoeksema et al. 1994).

\section{ROLE INVOLVEMENT}

The manner in which prevalence varies by gender, marital status and involvement in child care suggests that depression may be linked to the particular things that people do, and the cultural variation suggests that it is affected by the meaning they attach to what they do. This can be conceptualized in terms of roles, especially those that are influenced by sex. Most human behaviour can be defined as role-related, and roles have a central significance for self-definition and selfevaluation. Role attributes should thus be an important determinant of affective tone, and, further, of affective disorder. This hypothesis affords a conceptual link between social and attitudinal variables, and thus between social and cognitive theories of depression. It may also help our understanding of the differential impact of particular life events. Finally, it may offer a solution to the cultural plasticity of the macrosocial correlates of depression: a geographical difference in the value placed on individual roles may be reflected in differences in the sociodemographic characteristics of high risk.

Until recently, the treatment of roles in social psychiatry has been both superficial and speculative. Men and women differ in terms of the range and status of the roles they carry out, and they certainly differ in the satisfactions they obtain from them. A detailed and critical study of rolebased behaviour promises a major step forward in understanding sex differences in the frequency of affective disorder. Important developments in this area have been reported by Power and his colleagues (Lam \& Power, 1991; Champion \& Power, 1995) and by Nazroo et al. (1997). I have set out elsewhere the aspects of roles that are likely to be significant (Bebbington, 1996).

\section{CONCLUSION}

Surprisingly, it is possible to draw some reasonably firm conclusions from this literature, although they may be subject to revision from new and better research. The determinants of the sex difference differ from those involved in the aetiology of depressive disorder, particularly with regard to genetic factors and poor social support. However, the failure of genetic factors to account for the difference is a major setback for explanations in terms of sex-related biological factors. There seems no doubt that biological factors are involved in the emergence of depressive disorder, it is just difficult to argue that they are responsible for the sex difference. This pushes us towards a consideration of the physical and social environment. For depressive disorder the evidence about the environment is much better for social factors, and a plausible case can be made for a developmental perspective involving the interaction of social experience and psychological attributes. However, the sex difference is considerable and if its determinants are predominantly social, this emphasizes their contribution to the aetiology of depression as a whole.

These conclusions are in line with my own prejudices. I am wary of attempts to identify a biological 'inferiority' underlying the female proneness to depression. Such attempts have a long history, and were important in the development of psychiatric thought in Victorian times (Oppenheim, 1991). However, this is an area of dispute where there seem to be no neutrals: one would like to think that the issue might be resolved empirically, but this requires results of such clarity that the need for interpretation is minimal. Our sole current certainty is that we have not reached this stage.

PAUL E. BEBBINGTON 


\section{REFERENCES}

Abramson, L. Y., Seligman, M. E. P. \& Teasdale, J. D. (1978). Learned helplessness in humans: critique and reformulation. Journal of Abnormal Psychology 87, 49-74.

Abramson, L. Y., Metalsky, G. I. \& Alloy, L. B. (1989). Hopelessness: a theory-based subtype of depression. Psychological Review 96, 358-372.

Abramson, L. Y., Metalsky, G. I. \& Alloy, L. B. (1993). Hopelessness. In Symptoms of Depression (ed. C. G. Costello), pp. 180-205. Wiley: New York.

Akiskal, H. S. \& McKinney, W. T. (1975). Overview of recent research in depression: integration of ten conceptual models into a comprehensive clinical frame. Archives of General Psychiatry 32, 285-305.

Allen, R. E. \& Pitts, F. N. (1984). Dexamethasone suppression in depressed elderly outpatients. Journal of Clinical Psychiatry $\mathbf{4 5}$ 397-398.

Allen, D. M. \& Tarnowski, K. J. (1989). Depressive characteristics of physically abused children. Journal of Abnormal Child Psychology 17, $1-11$.

Alloway, R. \& Bebbington, P. E. (1987). The buffer theory of social support: a review of the literature. Psychological Medicine 17, 91-108.

Anderson, J. C., Williams, S., McGee, R. \& Silva, P. A. (1987). DSM-III disorders in preadolescent children. Archives of General Psychiatry 44, 69-76.

Angold, A. \& Rutter, M. (1992). Effects of age and pubertal status on depression in a large clinical sample. Developmental Psychopathology 4, 5-28.

Ansseau, M., Depauw, Y., Charles, G., Castro, P., D'Haenen, H., De-Vigne, J. P., Hubain, P., Legros, J. J., Pelc, I., Toscano, A. et al. (1987). Age and gender effects on the diagnostic power of the DST. Journal of Affective Disorders 12, 185-191.

Baldwin, J. A. (1971). Five Year Incidence of Reported Psychiatric Disorder. Aspects of the Epidemiology of Mental Illness: Studies in Record Linkage. Little Brown \& Co.: Boston.

Bebbington, P.E. (1988). The social epidemiology of clinical depression. In Handbook of Studies on Social Psychiatry (ed. A. S. Henderson and G. Burrows), pp. 89-102. Elsevier: Amsterdam.

Bebbington, P. E. (1994). The epidemiology of depressive illness. In Psychopharmacology of Depression (ed. S. A. Montgomery and T. H. Corn), pp. 1-18. Oxford Medical Publications: Oxford.

Bebbington, P. E. (1996). The origins of sex differences in depressive disorder: bridging the gap. International Review of Psychiatry $\mathbf{8}$, 295-332.

Bebbington, P., Hurry, J., Tennant, C., Sturt, E. \& Wing, J. K. $(1981 a)$. The epidemiology of mental disorders in Camberwell. Psychological Medicine 11, 561-580.

Bebbington, P. E., Tennant, C. \& Hurry, J. (1981b). Adversity and the nature of psychiatric disorder in the community. Journal of Affective Disorders 3, 345-366.

Bebbington, P. E., Sturt, E., Tennant, C. \& Hurry, J. (1984). Misfortune and resilience: a community study of women. Psychological Medicine 14, 347-364.

Bebbington, P. E., Tennant, C. \& Hurry, J. (1991). Adversity in groups with an increased risk of minor affective disorder. British Journal of Psychiatry 158, 33-40.

Bebbington, P. E., Jenkins, R., Lewis, G., Brugha, T., Farrell, M. \& Meltzer, H. (1998). The influence of age and sex on the prevalence of depressive conditions: report from the National Survey of Psychiatric Morbidity. Psychological Medicine 28, 9-19.

Beck, A. T., Rush, A. J., Shaw, B. F. \& Emery, G. (1980). Cognitive Therapy of Depression. John Wiley \& Sons: London.

Bifulco, A., Brown, G. W. \& Adler, Z. (1991). Early sexual abuse and clinical depression in adult life. British Journal of Psychiatry 159, 115-122.

Billings, A. \& Moos, R. H. (1984). Chronic and non-chronic unipolar depression: the differential role of environmental stressors and resources. Journal of Nervous and Mental Disease 172, 65-75.

Brewin, C. R. (1996). Cognitive processing of adverse experience. International Review of Psychiatry 8, 333-339.

Brooks-Gunn, J. \& Warren, M. P. (1989). Biological and social contributions to negative affect in young adolescent girls. Child Development 60, 40-55.

Brown, G. W. \& Birley, J. L. T. (1968). Crises and life changes and the onset of schizophrenia. Journal of Health and Social Behaviour 9, 203-214

Brown, G. W. \& Harris, T. (1978). Social Origins of Depression: A Study of Psychiatric Disorders in Women. Tavistock: London.

Bruder-Mattson, S. F. \& Hovanitz, C. A. (1990). Coping and attributional styles as predictors of depression. Journal of Clinical Psychology 46, 557-565.

Calicchia, J. P. \& Pardine, P. (1984). Attributional style: degree of depression, respondent's sex, and nature of the attributional event. Journal of Psychology 117, 167-175.

Carter, C. D. (1969). Genetics of common disorders. British Medical Bulletin 25, 52-57.

Champion, L. A. \& Power, M. J. (1995). Social and cognitive approaches to depression: towards a new synthesis. British Journal of Clinical Psychology 34, 485-503.

Checkley, S. (1996). Neuroendocrine changes in depression. International Review of Psychiatry 8, 373-378.

Cleary, P. D. \& Mechanic, D. (1983). Sex differences in psychological distress among married people. Journal of Health and Social Behaviour 6, 64-78

Cohen, P., Cohen, J. \& Brook, J. (1993). An epidemiological study of disorders in late childhood and adolescence. II. Persistence of disorders. Journal of Child Psychology and Psychiatry 34, 869-877.

Cooke, D. J. \& Hole, D. J. (1983). The importance of stressful life events. British Journal of Psychiatry 143, 397-400.

Dinan, T. G. (1994). Glucocorticoids and the genesis of depressive illness. A psychobiological model. British Journal of Psychiatry 164, 365-371.

Elliott, J. \& Huppert, F. A. (1991). In sickness and in health: associations between physical and mental well-being, employment and parental status in a British Nationwide sample of married women. Psychological Medicine 21, 515-524.

Ensel, W. M. (1982). The role of age in the relationship of gender and marital status to depression. Journal of Nervous and Mental Disease 170, 536-543.

Fleming, J. E. \& Offord, D. R. (1990). Epidemiology of childhood depressive disorders: a critical review. Journal of the American Academy of Child and Adolescent Psychiatry 29, 571-580.

Fondicaro, M. R. \& Moos, R. H. (1987). Social support and coping: a longitudinal analysis. American Journal of Community Psychology 15, 653-673.

Grad de Alarcon, J., Sainsbury, P. \& Costain, W. R. (1975). Incidence of referred mental illness in Chichester and Salisbury. Psychological Medicine 5, 32-54.

Haaga, D. A. F., Dyck, M. J. \& Ernst, D. (1991). Empirical status of cognitive theory of depression. Psychological Bulletin 110, 215-236.

Haw, C. E. (1995). The family life cycle: a forgotten variable in the study of women's employment and wellbeing. Psychological Medicine 25, 727-738.

Hirschfeld, R. M. A., Klerman, G. L., Clayton, P. J., Keller, M. B. \& Andreasen, N. C. (1984). Personality and gender-related differences in depression. Journal of Affective Disorders 7, 211-221.

Hobfoll, S. E., Dunahoo, C. L., Ben-Porath, Y. \& Monnier, J. (1994). Gender and coping: the dual-axis model of coping. American Journal of Community Psychology 22, 49-82.

Hunt, G. E., Johnson, G. F. \& Caterson, I. D. (1989). The effect of age on cortisol and plasma dexamethasone concentrations in depressed patients and controls. Journal of Affective Disorders 17, 21-32.

Jahoda, M. (1982). Employment and Unemployment. Cambridge University Press: Cambridge. 
Jorm, A. F. (1987). Sex and age differences in depression: a quantitative synthesis of published research. Australian and New Zealand Journal of Psychiatry 21, 46-53.

Kashani, J. H. \& Carlson, G. A. (1987). Seriously depressed preschoolers. American Journal of Psychiatry 144, 348-350.

Kessler, R. C. \& McLeod, J. D. (1984). Sex differences in vulnerability to undesirable events. American Sociological Review 49, 621-631.

Kessler, R. C. \& McRae, J. A. (1981). Trends in sex and psychological distress. American Sociological Review 46, 443-452.

Kessler, R. C., McGonagle, K. A., Swartz, M., Blazer, D. G. \& Nelson, C. B. (1993). Sex and depression in the National Comorbidity Survey, I: lifetime prevalence, chronicity and recurrence. Journal of Affective Disorders 29, 85-96.

Krause, N. \& Geyer-Pestello, H. F. (1985). Depressive symptoms among women employed outside the home. American Journal of Community Psychology 13, 49-67.

Kupfer, D. J., Frank, E., Carpenter, L. L. \& Neiswanger, K. (1989). Family history in recurrent depression. Journal of Affective Disorders 17, 113-119.

Kuyken, W. \& Brewin, C. R. (1994). Intrusive memories of childhood abuse during depressive episodes. Behaviour Research and Therapy 32, 525-528.

Lam, D. H. \& Power, M. J. (1991). Questionnaire designed to assess roles and goals: a preliminary study. British Journal of Medical Psychology 64, 359-373.

Lewinsohn, P. M., Steinmetz, J. L., Larson, D. W. \& Franklin, J. (1981). Depression related cognitions: antecedent or consequence? Journal of Abnormal Psychology 90, 213-219.

Loewenthal, K., Goldblatt, V., Gorton, T., Lubitsch, G., Bicknell, H., Fellowes, D. \& Sowden, A. (1995). Gender and depression in Anglo-Jewry. Psychological Medicine 25, 1051-1064.

McGee, R., Williams, S., Kashani, J. \& Silva, P. (1983). Prevalence of self-reported depressive symptoms and associated factors in mothers in Dunedin. British Journal of Psychiatry 143, 473-479.

Maes, M., DeRuyter, M. \& Suy, E. (1989a). Use of the dexamethasone suppression test in an inpatient setting: a replication and new findings. Psychoneuroendocrinology 14, 231-139.

Martin, D. J., Abramson, L. Y. \& Alloy, L. B. (1984). Illusion of control for self and others in depressed and nondepressed college students. Journal of Personality and Social Psychology 46, 125-136.

Mavreas, V. G., Beis, A., Mouyias, A., Rigoni, F. \& Lyketsos, G. C. (1986). Prevalence of psychiatric disorder in Athens: a community study. Social Psychiatry 21, 172-181.

Meltzer, H., Gill, B., Petticrew, M. \& Hinds, K. (1995). The Prevalence of Psychiatric Morbidity Among Adults Living in Private Households. OPCS Survey of Psychiatric Morbidity in Great Britain. Report 1. HMSO: London.

Merikangas, K. R., Weissman, M. M. \& Pauls, D. L. (1985). Genetic factors in the sex ratio of major depression. Psychological Medicine 15, 63-69.

Moss, P. \& Plewis, I. (1977). Mental distress in mothers of pre-school children in Inner London. Psychological Medicine 7, 641-652.

Nazroo, J. Y., Edwards, A. C. \& Brown, G. W. (1997). Gender differences in the onset of depression following a shared life event: a study of couples. Psychological Medicine 27, 9-19.

Nolen-Hoeksema, S. (1987). Sex differences in unipolar depression: evidence and theory. Psychological Bulletin 101, 259-282.

Nolen-Hoeksema, S. (1990). Sex Differences in Depression. Stanford University Press: Stanford, CA.

Nolen-Hoeksema, S., Parker, L. E. \& Larson, J. (1994). Ruminative coping with depressed mood following loss. Journal of Personality and Social Psychology 67, 92-104.

Nuttall, R. \& Jackson, H. (1994). Personal history of childhood abuse among clinicians. Child Abuse and Neglect 18, 455-472.

Oppenheim, J. (1991). Shattered Nerves. Doctors Patients and Depression in Victorian England. Oxford University Press: Oxford.

Paikoff, R. L., Brooks-Gunn, J. \& Worren, M. P. (1991). Effects of girls' hormonal status on depressive and aggressive symptoms over the course of one year. Journal of Youth and Adolescence 20, $191-215$.
Parry, G. (1986). Paid employment, life events, social support and mental health in working class mothers. Journal of Health and Social Behaviour 27, 193-208.

Patton, G. C., Hibbert, M. E., Carlin, J., Shao, Q., Rossier, M., Caust, J. \& Bowes, G. (1996). Menarche and the onset of depression and anxiety in Victoria, Australia. Journal of Epidemiology and Community Health 50, 661-666.

Paykel, E. S. \& Rowan, P. (1979). Recent advances in research on affective disorders. In Recent Advances in Clinical Psychiatry (ed. E. S. Paykel). Edinburgh, Churchill Livingstone.

Pearlin, L. I. \& Johnson, J. S. (1977). Marital status, life strains and depression. American Sociological Review 42, 704-715.

Pearlin, L. I. \& Lieberman, M. A. (1977). Social sources of emotional distress. In Research in Community and Mental Health (ed. R. Simmons). JAI Press: Greenwich, Connecticutt.

Perugi, G., Musetti, L., Simonini, E., Piagentini, F., Cassano, G. B. \& Akiskal, H. S. (1990). Gender-mediated clinical features of depressive illness. The importance of temperamental differences. British Journal of Psychiatry 157, 435-841.

Power, M. S. (1990). A prime time for emotion: cognative vulnerability and the emotional disorders. In Lines of Thinking, vol. 2. (ed. K. J. Gilhooly, M. J. G. Keane, R. H. Logie and G. Erodos), pp. 157-165. Wiley: Chichester.

Radloff, L. (1975). Sex differences in depression: the effects of occupation and marital status. Sex Roles 1, 249-265.

Richman, N. (1974). The effect of housing on pre-school children and their mothers. Developmental Medicine and Child Neurology 16, $53-58$.

Richman, N. (1977). Behaviour problems in preschool children: family and social factors. British Journal of Psychiatry 131, 523-527.

Roberts, R. E. \& O'Keefe, S. J. (1981). Sex differences in depression re-examined. Journal of Health and Social Behaviour 22, 394-400.

Roberts, C. R., Roberts, R. E. \& Stevenson, J. M. (1982). Women, work, social support and psychiatric morbidity. Social Psychiatry 17, 167-173.

Roesler, T. A. \& McKenzie, N. (1994). Effects of childhood trauma on psychological functioning in adults sexually abused as children. Journals of Nervous and Mental Diseases 182, 145-150.

Romans-Clarkson, S. E., Walton, V. A., Herbison, G. P. \& Mullen, P. E. (1988). Marriage, motherhood and psychiatric morbidity in New Zealand. Psychological Medicine 18, 983-990.

Rose, D. T., Abramson, L. Y., Hodulik, C. J., Halberstadt, L. \& Leff, G. (1994). Heterogeneity of cognitive style among depressed inpatients. Journal of Abnormal Psychology 103, 419-429.

Rutter, M. (1991). Age changes in depressive disorders: Some developmental considerations. In The Development of Emotion Regulation and Dysregulation (ed. J. Garber and K. A. Dodge), pp. 273-300. Cambridge University Press: Cambridge.

Rutter, M., Tizard, J., Yule, W., Graham, P. \& Whitmore, K. (1976). Research report: Isle of Wight studies, 1964-1974. Psychological Medicine 6, 313-332.

Sowa, C. J. \& Lustman, P. J. (1984). Gender differences in rating stressful events, depression, and depressive cognition. Journal of Clinical Psychology 40, 1334-1337.

Srole, L. \& Fischer, A. K. (1980). The midtown Manhattan longitudinal study vs 'the mental paradise lost' doctrine: a controversy joined. Archives of General Psychiatry 37, 209-221.

Teasdale, J. D. (1995). Clinically relevant theory: integrating clinical insight with cognitive sciences. In Frontiers of Cognitive Therapy (ed. P. Salkovskis and D. M. Clark), pp. 26-47. Guilford Press: London.

Teasdale, J. D. \& Barnard, P. J. (1993). Affect, Cognition and Change: Remodelling Depressive Thought. Lawrence Erlbaum Associates: Hove.

Thoits, P. A. (1982). Life stress, social support and psychological vulnerability: epidemiological considerations. Journal of Community Psychology 10, 341-62.

Turner, R. J. \& Avison, W. R. (1989). Gender and depression: 
assessing exposure and vulnerabilty to life events in a chronically strained population. Journal of Nervous and Mental Disease 177, 443-455.

Turner, R. J. \& Marino, F. (1994). Social support and social structure: a descriptive epidemiology. Journal of Health and Social Behaviour 35, 193-212.

Uhlenhuth, E. H. \& Paykel, E. S. (1973a). Symptom intensity and life events. Archives of General Psychiatry 28, 473-477.

Uhlenhuth, E. H. \& Paykel, E. S. (1973b). Symptom configuration and life events. Archives of General Psychiatry 28, 744-748.

Uhlenhuth, E. H., Lipmann, R. S., Balter, M. B. \& Stern, M. (1974). Symptom intensity and life stress in the city. Archives of General Psychiatry 31, 759-764.

Vázquez-Barquero, J-L., Diez-Manrique, J. F., Peña, C., Aldana, J.,
Samaniego-Rodriguez, C., Menendez-Arango, J. \& Mirapeix, C. (1987). A community mental health survey in Cantabria: a general description of morbidity. Psychological Medicine 17, 227-242.

Warr, P. \& Parry, G. (1982). Paid employment and women's psychological well-being. Psychological Bulletin 91, 498-516.

Weissman, M. M. \& Klerman, G. L. (1977). Sex differences and the epidemiology of depression. Archives of General Psychiatry 3, 98-112.

Weissman, M. M., Leaf, P. J., Holzer, C. E., Myers, J. K. \& Tischler, G. L. (1984). The epidemiology of depression: an update on sex differences in rates. Journal of Affective Disorders 7, 179-188.

Wolk, S. I. \& Weissman, M. M. (1995). Women and depression. In Review of Psychiatry, vol. 14, (ed. J. M. Oldham and M. B. Riba), pp. 227-259. American Psychiatric Press: Washington, DC. 